Perspective

\title{
Big Fire; or, Introducing the Pyrocene
}

\section{Stephen Pyne}

School of Life Sciences, Arizona State University, Box 874501, Tempe, AZ 85287, USA; stephen.pyne@asu.edu

Received: 13 October 2017; Accepted: 21 October 2017; Published: 23 October 2017

\begin{abstract}
I present the case for a fire-centric scholarship, and suggest the transition between burning living landscapes and lithic ones (in the form of fossil fuels) would make a good demonstration of what such scholarship might do and what its value could be.
\end{abstract}

Keywords: fire scholarship; fire science; pyric transition; industrial fire

\section{Quest for Fire}

The only fire department on a university campus is the one that sends emergency vehicles when an alarm sounds. This will be a tired trope if I keep using it, but it illustrates a fundamental quandary for those of us who are interested in fire as fire, and not as a subset of other disciplines. The other ancient elements have whole departments devoted to their study. Fire does not. It has no academic home of its own. It has no organizing concept. It is, intellectually, what it is in nature: a synthesis of its surroundings.

Does this matter? It does if we want academic legitimacy, or at least respect, and it matters if it improves our understanding of fire. It matters less if we are concerned about translating that understanding into practice. The general theory of relativity is core to physics and cosmology. It isn't for launching rockets or designing driverless cars. Fire-related problems will likely be the provenience of teams, each member of which brings a particular specialty. The integration will come by project, not by a shared vision of fire.

But perhaps fire as a concept can be more. What theme might illustrate such an argument? And might also demonstrate the analytic and synthetic power of a fire-centric scholarship? What topic might let big ecology, big history, and big fire overlap?

\section{Pyric Transition}

My candidate is the planetary inflection that occurred when the Earth's keystone species for fire began to burn lithic landscapes instead of living ones. We don't have a good name for this moment. I like to call the new combustion regime based on fossil biomass industrial fire, and the shift the pyric transition, by analogy to the better-documented demographic transition in which a society's population first explodes, then collapses as industrialization matures. Something analogous seems to happen with the population of fires. Most developing countries have an excess of bad burns; most developed countries today have a fire load below ecological replacement value and struggle to boost good burning.

These terms (and the concepts behind them) haven't found purchase. In truth, they only seem to confuse. There have been several transitions in humanity's relationship with fire, and the expression pyric transition seems to migrate among them. We need a term that identifies specifically with fire's industrial revolution, when humanity's long quest for fire shifted from the problem of finding more stuff to burn to coping with the consequences of all that burning, when fire's sinks come to matter more than fire's sources.

This is not a trivial topic. Humanity's firepower is its ecological signature, what we do that no other creature does. The escalation of our firepower through industrial combustion underwrites the 
Anthropocene; so much so, that we might relabel that era the Pyrocene. A lot of research has inquired into the meaning of this transition for the atmosphere and climate change, and for what this promises for the Earth System and its future fires. This formulation privileges a physical model of fire and the kinds of responses such a model understands.

Yet the transition directly affects Earth's biosphere. It means that fire regimes that humans have shaped or, in some cases, imposed for centuries or millennia unravel because people have relocated their burning into machines or off-site, or have applied their mechanical firepower to suppress open burning. An excess of fire in some places, a deficit in others-these are direct consequences of the pyric transition. They exist apart from climate change induced by fossil-fuel combustion.

So, too, has industrial fire reorganized human societies. It redefines what, in nature, are resources, how people live on the land, how they organize their economies and connect markets, how they relate to fire. It magnifies our firepower exponentially. It makes the wildland-urban interface possible. It encourages nature preserves. It dispatches engines and airtankers. For the past 150 years, various societies have tried to reconcile their firepower with its ecological knock-on effects. We are still cataloguing the collateral damages. Industrial societies tend to suppress flame; non-industrial, to promote flame. So far, however, industrial combustion has stood beyond the pale of landscape fire and its study.

The two realms of earthly fire do not seem to coexist outside the riotous period of transition from one to the other. Today, we seem to have three categories of combustion: natural fire, anthropogenic fire in living landscapes, and anthropogenic fire from burning lithic landscapes. How to divide three kinds of fire into two realms of combustion and have something left over is the challenge of fire sustainability. Surely, a fire-centric perspective would help us understand better how these pieces jostle among themselves.

\section{Fire as Focus}

Abstraction is the bane and blessing of academic study. If fire wants a place in the academy or the realm of high culture, it will have to be more than the sum of individual subdisciplines. It's not just that fire-related topics need a place to go, but that they need a place to flourish together, not merely wander in and out of the intellectual equivalent of a homeless shelter.

A Grand Unified Theory of fire would be an interesting exercise. It would also likely be a quixotic and unnecessary pursuit in seeking to join all the many scholarships that fire touches, from physics to philosophy, under a common methodology or model. The search for a single organizing principle may represent little more than a secularization of modern science's Judeo-Christian heritage, with everything joined under a single jealous Purpose. In truth, there are several such unified theories possible, each (like non-Euclidean geometries) whole and consistent. Physics offers one such paradigm, but so does biology; fire after all is a product of the living world [1].

What do we gain by making fire the focus of inquiry? We would understand better what makes Earth what it is as a planet. We would understand better what it means to be human. We would see other disciplines in new light. Fire has been on Earth since plants colonized the continents, but barely enters into general biology texts; climate history, too, is becoming a subset of fire history. A fire-centric perspective furnishes a usable narrative for the Anthropocene, one that allows us to understand its full ramifications and the indispensable role of humans. It would permit us to interpret industrialization in a different way; fast-developing countries like China and India furnish a nifty test on what industrialization means for fire's ecology. It could encourage a search for new metrics, an attractive research agenda for the quantitatively minded.

Fire's project has to start somewhere. The future of fire science and scholarship-on fire as a serious presence in contemporary discourse beyond its role as a disaster and an academic step-child-will depend on how we argue the case. The Anthropocene is a good hook, since it speaks to issues of some urgency for a wide population. The pyric transition makes a useful organizing 
concept and test case, a demonstration of what a more fire-centric scholarship can do. Of course our intellectual terrain abounds with other candidates, but this is the hill I would choose to climb.

Conflicts of Interest: The author declares no conflict of interest.

\section{Reference}

1. Pyne, S.J. Problems, paradoxes, paradigms: triangulating fire research. Int. J. Wildland Fire 2007, 16, $271-276$. [CrossRef]

(c) 2017 by the author. Licensee MDPI, Basel, Switzerland. This article is an open access article distributed under the terms and conditions of the Creative Commons Attribution (CC BY) license (http:/ / creativecommons.org/licenses/by/4.0/). 